\title{
CLIMATE CHANGE AND SUSTAINABLE FUTURES
}

\section{Introduction}

A key issue in relation to achieving a sustainable future is the maintenance of an equitable climate (Pittock, 2005 pg 1). The climate and temperature on the surface of the planet are a result of the properties of the particular gases in the atmosphere. Carbon Dioxide which comprises $0.1 \%$ of the atmosphere (a so-called greenhouse gas) is particularly important because without it the temperatures on the earth's surface would be $31^{\circ} \mathrm{C}$ below the temperature it is today. (Ruddiman, 2001).

However, the delicate balance between these gases has been disturbed. The concentration of greenhouse gases has grown sharply since the 1750s and has increased further since the Industrial Revolution in the late $18^{\text {th }}$ and early $19^{\text {th }}$ Century (Intergovernmental Panel on Climate Change, IPCC, 2007). The IPCC is an international panel of experts set up by Government throughout the world to explore and research the issues of climate change.

Carbon dioxide levels have increased massively over the past decade from 280 ppm in the pre-industrial era to 380 ppm in 2005 (Stem, 2006, pg 4). If we add the effect of other greenhouse gases such as methane we currently have the equivalent of 430ppm of carbon dioxide in the atmosphere.

Greenhouse gases in the atmosphere are rising by $2.3 \mathrm{ppm}$ of $\mathrm{CO}_{2}$ equivalent per year and are now higher than any time in the last 650,000 years (Stern, p6). It is estimated that world-wide temperatures have risen by $0.7^{\circ} \mathrm{C}$ since 1900 and the ten warmest years have all occurred since 1990 .

The mass of evidence available has caused the IPCC to conclude that global warming is being caused 'primarily by human activities'. Such activities include power/energy production, land use, transport, agriculture and industry (Stern, op cit).

Thus past and likely future emissions provide a major threat to a sustainable future. In an attempt to paint a realistic picture of what the future holds, given the current and possible future emissions the IPCC produced a special report on emissions scenarios (IPCC, 2000). All scenarios are worked through until the year 2100 and all show levels of emissions that would cause irreversible damage to the future environment.

Members of the IPCC generally have a scientific training. The philosophical basis of the scientific approach is not to make definitive conclusions until a very high standard of proof has been established. There are very good reasons for this approach but in the field of climate science this may result in dangers not being taken into account because a high enough level of proof has not been achieved. This might result in delay in taking essential precautions. In particular, there are particular concerns related to so call feedback mechanisms which are not widely understood and have only recently been studied in depth 
Results from new risk based assessments suggest that there is a significant chance that the climate system is more sensitive to feedback mechanisms than originally thought

Such feedback mechanisms relate to weakening of the capacity of Earth's natural sinks ability to absorb carbon dioxide or for the diminishing ice caps to reflect radiation (see Friedlingstein et al, 2006), further depletion of rainforests (Cox et al, 2000) and the potential for thawing of permafrost and frozen peat bogs releasing methane, a very powerful climate change gas, (Gorham, 1991). There are also huge quantities of methane stored under pressure at the bottom of the ocean. The worry is that beyond a particular (but unknown) trigger point much larger volumes of greenhouse could start to be emitted with the resulting temperature increase releasing still further volumes.... This could lead to runaway climate change and this is what commentators are alluding to when discussing 'dangerous climate change'

\section{Implications of Climate Change for Sustainability}

An equitable climate is a public good and those bringing about climate change are imposing costs in the rest of the world. (Stern, 2006). A particular problem is that impacts are persistent, global and lagged and that the perpetrators do not suffer the full consequences of their actions. Consequences of climate change which lead to unsustainable future will include

Melting glaciers - with consequences of increased flooding during the wet season and water shortage during the dry season. This is likely to be an important issue in the Indian subcontinent, part of China and the Andes

Declining crop yields - higher temperatures are likely result in reduced crop yields in tropical areas. This may not be offset by increasing yields at mid to high latitudes. Africa is likely to be particularly affected

Ocean acidification - will rise from increasing absorption of carbon dioxide with effects on marine eco-systems and possible adverse consequences for fish stocks.

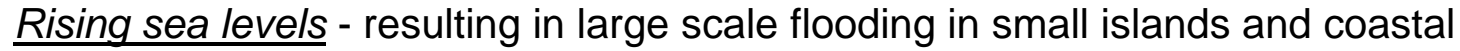
cities

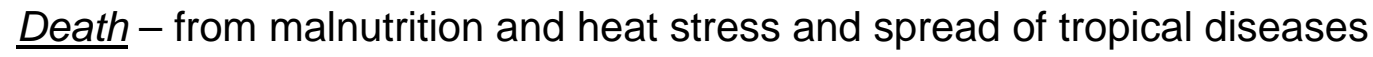

Displacement of population - due to rising sea levels, heavier floods and more intense drought

Loss of Biodiversity - ecosystems will become increasingly vulnerable 
Climate change is likely to cause deep inequalities both within and between countries. Developing countries will suffer a double inequality; although not primarily responsible for climate change they will face the most severe consequences particularly flooding, water shortages and declining crop yields (Pittock, 2005, Chapter 6). There are also issues related to intergenerational equity -not passing a degraded environment to future generations and stewardship - passing on aspects of the world at least as good as those inherited from previous generations.

Although adaptation measures may be taken in order to limit the impact of climate change a sustainable future depends on stabilizing the level of greenhouse gases in the atmosphere at a level low enough to prevent dangerous climate change. Developing countries lack resources and therefore are likely to find adaptation more difficult than developed countries

\section{Establishing an Emissions Target}

We have already noted that greenhouse gas concentration in the atmosphere now stands at $430 \mathrm{ppm}$ of $\mathrm{CO}_{2}$ equivalent compared with only $280 \mathrm{ppm}$ before the industrial revolution.

Emissions are still rising by $2-3$ ppm per year according to Stern (2006, $p$ 201). Such a scenario might result in a temperature rise of over $6{ }^{\circ} \mathrm{C}$ by the end of the century and a major risk of runaway global warming. Stern suggests a focus on a stabilisation range of $450-550 \mathrm{ppm}$. To stabilise below 450 ppm would be very expensive and likely to result in economic dislocation. A level of more than 550 ppm would, however, be too risky

Meinshausen et al (2006) have summarised projections from eleven recent studies on the relationship between stabilisation levels of greenhouse gas and likely temperature rise. This shows that even if we do manage to stabilise in the $450-550 \mathrm{pmm}$ range, studies predict the probabilities between $63 \%$ and $99 \%$ of a temperature rise of more than $2^{\circ} \mathrm{C}$. Such a rise in temperature likely to have significance consequences in terms of decrease in water availability, crop yields, costal flooding and biodiversity (See Stern page 66 and 67). In order to reach stability at 550 ppm global emissions need to peak in the next 20 years and to fall $3 \%$ a year from then. Emissions would need to be $25 \%$ lower by 2050 and reduced by $80 \%$ in the longer term. To put this in context, the 'dash for gas' in the UK reduced emissions by about 1\% p.a. in the UK and the collapse of the Russian economy in the 1990s reduced emissions by about $5 \%$ p.a.

\section{The Economics of Emissions Reduction}

One of the major problems of making rapid reduction in emissions is that current capital stocks lock the economy into particular emission patterns for significant time periods. For example, a coal fired power station would have a lifetime of 45 years, an aircraft for 25 years etc. Furthermore, development of lower emission technologies takes time as does changing old habitats, preferences and institutional structures. There are however a range of 
technological options that could be adopted to reduce emissions. These include reducing demand for energy, improving energy efficiency, reducing non fossil fuel emissions (e $g$ agriculture) and switching to low carbon technologies. Various economic models to estimate the cost of emission stabilization have been developed such as those of Tol (2002) and Nordhaus and Boyer (2000). Stern has used three approaches - resource cost (chapter 9), macroeconomic modelling (chapter 10) and the social cost of Carbon (chapter 13). Stern's analysis showed that stabilising carbon emissions to meet the $550 \mathrm{ppm}$ target resulted in 1\% reduction in GDP compared with the Business as Usual (BAU) scenarios. Unfortunately the cost of stabilisation in the 400-450 ppm range would be three times as much. The above reductions, however, are not $1 \%$ of current GDP but of a vastly expanded future GDP. Ignoring emission and continuing on a business as usual strategy could reduce GDP by more than $20 \%$.

There would also be positive aspects of the above such as significant business opportunities in the low emissions technologies. Other important benefits might include trading in carbon markets, more micro generation, improved business efficiency, energy security and opportunities to phase out fuel subsidies (see for example, The Climate Group (2005))

Various policies have been advocated to enable sustainable emissions to be achieved. These might include establishing an appropriate world wide carbon price, supporting low emission technological innovations and removing barriers to behavioural change.

There are a number of options for Carbon pricing these include regulations, command and control carbon taxes and emissions trading.

\section{Critical approaches and the importance of choice of discount rate}

There was a wide range of positive responses to the Stem review, including UK institutions such as representatives of UK business (Confederation of British Industry, $\mathrm{CBI}$ ), trade unionists (Trade Union Congress) and Environmental Pressure Groups such as a Greenpeace. Support also came from the World Bank and the Secretary General of the UN.

Negative responses were received from a diminishing group of climate change deniers. In addition Prof Tol of the IPCC and economist Robert Mendelssohn and some others claimed that Stem overestimated the cost of climate change because of his choice of a low discount rate.

To discuss these issues we need to note the methodology for evaluating decision involving future cash flows. Generally we prefer current cash- flows to future ones and, as a result, future cash flows are discounted. The further in the future that they occur, the greater is the degree of discounting. An appropriate discount rate needs to be chosen. The choice of discount rate is very important. For example a cash flow of $£ 1$ in 50 years time at 1\% discount rate will be worth 74.2 pence, while with a $5 \%$ discount rate it would be worth 23.1p. This high discount will result in future costs and benefits 
being highly devalued Stern notes that discounting is generally used to evaluate marginal decisions around a particular future path (for example one might be choosing between two cement plants with different start up and operating costs). Policy approaches to climate change are not, however, marginal decisions and Stern notes that future generations are not represented in discussions of appropriate discount rates ( $p$ 35). There may, therefore, be ethical problems in discounting purely on the basis that current consumption is preferred to future consumption.

"If little or no value was placed on prospects for the long run future, then climate change would be seen as much less of a problem. If, however, one thinks about the ethics in terms of most ethical frameworks, there is every reason to take these prospects very seriously".

This forms the philosophical justification for the relatively low discount rate adopted by Stern which account for much of the dispute with his critics.

\section{International Cooperation and Sustainable Futures}

Emission of climate change gases have a global effect no matter where the source is. Thus, there are similarities with other issues such as fishing depletion and protection of the ozone layer in that there is no supranational authority to undertake coercive action. Thus cooperation becomes the only feasible way forward. A number of international meetings have been held and some agreements have been achieved. These include:-

1989 Setting up the IPCC

$1992 \quad$ UN Framework on Climate Change

$1997 \quad$ Kyoto protocol (effective 2005)

2005 G8 Summit, Gleneagles

$2005 \quad$ Asian - Pacific Partnership

2007 Bali Conference

The Kyoto protocol had an objective to reduce emissions to 5\% below 1990 levels by 2012.(UNFCC, 2006) Target reductions were set for developed countries, the EU for example, had an 8\% target. Developing countries did not have formal targets but nevertheless, were expected to endeavour to moderate their emissions. Even at the time of signing it was realised that a reduction of $5 \%$ below 1990 level was insufficient for sustainability. Nevertheless, it provided an opportunity for the developed world to demonstrate to the developing countries that it was serious about climate change and prepared to make its contribution. It became increasingly evident that only a firm and binding commitment by developed countries to reduce emissions could send a signal strong enough to convince businesses, communities and individuals to act on climate change. It was hoped that this would enable a more comprehensive and stringent agreement to be signed when Kyoto expires at the end of 2012. 
Unfortunately the Kyoto protocol took eight years to come into force became the protocol had to be ratified by nations accounting for at least $55 \%$ of greenhouse gas emissions (BBC, 2005). The lack of support from the Bush administration in the USA made a significant contribution to this delay. Australia delayed signing the protocol until the election of the Kevin Rudd administration in late 2007. The protocol however did come into force in $16^{\text {th }}$ February 2005. Following this the EU has set up a carbon trading scheme.

The Bali Conference in 2007 resulted in a decision to hold a Conference in Copenhagen in 2009 at which attempts will be made to agree national emissions reductions

\section{Impediments to International Agreements}

One of the reasons that agreements over climate change are so difficult is that, historically, developed countries have made the major contributions to past emissions (around 70\%). According to Pittock, developing countries should be compensated and assisted by richer countries if they are to reduce their reliance on fossil fuels. Given recent growth rates, it is likely that developing countries such as India and China will make massive additions to emissions in future decades so the cooperation of developing countries is essential. Athanasiou and Baer (2002) warn that any treaty which indefinitely restricts a Chinese and or Indian to permanently lower emissions than an American (or European) will not be acceptable.

\section{Insights from Game Theory}

Game Theory is a tool which has been used in a variety of fields such as Economics, Management Science and Psychology to explore a wide range of cooperative situations. One game known as prisoners' dilemma, (Friedman, 1986), is particularly important in negotiation of certain types of cooperative agreement. A typical example of this game is given below in which two players have available competitive and non-competitive strategies. Pay offs from a combination of strategies are given as:

(player 1 pay off, player 2 pay off)

$$
\begin{aligned}
& \text { Player (2) } \\
& \text { NC } \quad \frac{\mathrm{NC}}{(-2,-2)}+\stackrel{\underline{\mathrm{C}}}{+1,-3)} \\
& \text { C }(-3,+1) \quad(0,0)
\end{aligned}
$$

Thus if player 1 plays a cooperative strategy and player 2 plays a noncooperative strategy, player 1 will receive -3 , and player 2 will receive +1 .

If we now look at the game purely from the point of view of player 1 , we get the following: 


\begin{tabular}{cccc} 
& & \multicolumn{2}{c}{ Player (2) } \\
& & $\underline{\mathrm{C}}$ & $\underline{ }$ \\
& NC & -2 & +1 \\
& & & \\
& $C$ & -3 & 0
\end{tabular}

It can be seen that whatever strategy player 2 adopts, the non-cooperative strategy will always be best for player 1 (i.e. it is dominant). Player 2 will perceive exactly the same game and recognise the same dominant strategy. Adopting the non-cooperative strategy, however, will leave them with a pay off of $(-2,-2)$ whereas if they had acted cooperatively they would have obtained a pay off of $(0,0)$. Climate change negotiations can be considered to be a game of prisoners dilemma in that the strategy not to reduce your emissions will always dominate.

Repeated games, however, which increase the frequency of contact and enhance transparency, contribute to building cooperation just as institutional structures and repeated negotiations do in international agreements (Axelrod, 1984). In addition, in repeated games options for renegotiations of the rules at key stages play an important role.(Farrell and Maskin,1989)

\section{Problems of Accountability and Democracy}

We have already touched on some of the major problems of democracy and accountability. One is that emissions of greenhouse gases emitted anywhere in the world will soon be evenly distributed globally so that costs will be shared equally between the emitters and non-emitters. Until recently there was doubt about whether human activity was in fact a driver of climate change and this was exploited, particularly by the Bush administration, as a reason for delaying action. This is now a less significant factor as only few contrarians still cast doubt in the existence of climate change. A further problem is the lag between emissions and their effects which mean that individuals and organisations need to forgo current consumption for probabilistic gains in the future. Here there maybe some analogies with the frog. If a frog is thrown into a pan of very hot water it will immediately jump out. If on the other hand if it is put into a pot of lukewarm water whose temperature is slowly raised it is likely to remain there, taking no action, until it expires.

A further problem is to decide who should be involved in the process of democratic choice. Future generations will not be represented in this decision making process, but will obviously be hugely affected by decisions taken, particularly if it results in them living in a massively degraded environment. 
Thus, there are major issues of equity. Firstly, equity within countries, secondly equity between countries and finally, equity between generations. The point is sometimes made that the electoral timescale is too short compared with the timescale of the continuous action that will be required to countries climate change. Focus is, therefore, often on a short term issues

Nevertheless, electorates can take climate change into consideration in making their verdict on a Government. In this respect, the Australian general election of 2007 is interesting. Here, the Australian economy was booming and on a historical basis the government should have won the election easily. Nevertheless, the Government was heavily defeated. There is little doubt that the issue of climate change was a major factor in this outcome. Although policy differences at the time of the election between parties was small, the Prime Minister, John Howard was well-known for his previously contrarian views on climate change and, in particular, for his refusal to sign the Kyoto protocol in spite of the fact that it was generally agreed that Australia had secured itself a particular generous deal. We may speculate on the reason for this election result, perhaps a well informed electorate or maybe that the effects of climate change, particularly in terms of widespread and prolonged droughts, were becoming more apparent. The fact that the election winner, Kevin Rudd signed the Kyoto protocol on his very first day in office applies to be quite significant.

On the other hand in the UK, support for measures to combat climate change seems to be crumbling under the pressure of negative economic developments.

A quote in the Observer newspaper, 25 $5^{\text {th }}$ May 2008 stated "David Cameron meanwhile faces an internally party row over his commitment to green taxes in the light of the Credit Crunch......... traditionalists want him to ditch proposed levies on low cost flights and on high polluting cars

Cameron built his reputation on green issues, cycling to work and travelling to the Arctic to inspect melting glaciers but it seems that his advisors are sceptical of the appeal of green issues when family finances are stretched".

The UK Government meanwhile has scrapped plans to put taxes on household waste and has abandoned plans for trials on carbon rationing. There is also pressure for reduction of taxes on fuel in the light of recent rapid rises in oil prices.

Thus, as expected, there are problems in maintaining commitment to sustainability once the economic situation becomes more difficult. This is a matter of concern because inevitably there will be economic setbacks from time to time. Institutions with a longer perspective than the next election are vital. Pressure groups may therefore play an important role in ensuring that appropriate pressure continues to be exercised.

A recent poll in the Observer news paper carried out by Ipsos-Mori (June 22 
$\left.{ }^{n d}\right)$ also gives concern about the strength of support for the tackling climate change in the UK. In this poll 1039 adults were surveyed and $60 \%$ agreed 'that many scientific experts still question if humans are responsible for climate change.' Around $40 \%$ agreed with the statement that 'climate change may not be as bad as people say'. In both cases about $20 \%$ were not convinced either way.

It should be noted that the questions are contaminated by acquiescence bias and it would have been interesting to see the results if the questions had been set out the other way. Nevertheless, some contradictory attitudes were demonstrated. Three quarters said they were concerned about climate change and two-thirds wanted the Government to do more. On the other hand there was quite a lot of cynicism about government initiatives such as green taxes which seem to be regarded as 'stealth taxes'. This is a line of thinking that the press has done much to encourage. The factors most strongly linked to concern about climate change were being a graduate, a member of socioeconomic class $A$ and $B$ and high income levels

Many respondents did not want to restrict their lifestyles and only a small minority were prepared to make significant changes such as driving and flying less. Jonathon Porritt who chairs the Government's Sustainable development commission point out the political risks involved and is quoted as saying

'Politicians need the context in which they are developing new policies to be a lot stronger and more positive. Otherwise the potential for backlash and unpopularity is considerable'

This study indicates that significant cultural change may be needed before completely successful climate change policies are achieved. Unfortunately time may be limited. We may note that conclusive information about the health risks of smoking was available in the early 1950s but it took many years for smoking levels to significantly drop and only very recently was legislation introduced to ban smoking in public places. This kind of timescale is not available to us. We shall need to examine whether Social Marketing can provide any kind of support.

\section{The Contribution of Social Marketing}

Commercial marketers demonstrate a capacity to bring about voluntary behaviour change in terms of increasing consumption of products from CocaCola to motor vehicles. Thus a key issue is to what extent these approaches might be employed in pursuing social objectives. This leads to the term social marketing as defined by Lazer and Kelly (1973).

"Social marketing is concerned with the application of marketing knowledge, concepts and techniques to enhance social as well as economic ends. It is also concerned with analysis of the social consequences of marketing". 
Kotler et al (2002) and Hastings (2006) have also provided basic texts on social marketing.

Social marketing goes far beyond issues of simple communication and may include individual citizens, stakeholders and policy makers. For example, consider a young person's smoking habit. This can be considered to arise partly from personal volition but partly through other factors such as whether friends and family smoke, whether tobacco supplies are widely available and wider social norms such as whether advertising and smoking in public places is allowed.

Avoidance of climate change depends partly on fear of the consequences. There is evidence that fear works up to a particular threshold and then becomes increasingly counter-productive. Rogers (1975) has developed an expectancy valence model that states effectiveness is a function of the magnitude of threat, probability of occurrence and the efficiency of the protective action that might be employed.

Social marketing also tries to tackle issues related to competition. In competitive terms the socially desirable action can be portrayed as hard work, unattractive and worthy. For example, a bad diet can be regarded fun and indulgent and a good one as boring. It is also problematic to asking people to give up things such as chocolate, cigarettes, and driving a $4 \times 4$. According to Layard we put a greater premium on a loss than a gain. The angst suffered from a $£ 100$ loss is thus quantitatively greater than satisfaction gained from $t a$ $£ 100$ wind-fall.

Thus, we need to present the above changes in a positive way. Insurance companies, for example, try to sell their products particularly by focussing on reassurance.

The Journal Communication, Cooperation participation, Research and Practice for a Sustainable Future is of interest since it focused on issues in the way that communication may influence attitude towards climate change. 


\section{Bibliography}

Athanasiou $T$ and 'Dead Heat, Global Justice and Global Warming' Seven Baer P (2002) Sisters Press, New York

Axelrod R (1985) 'The Evolution of Cooperation', New York, Basic Books

BBC (2005) Kyoto Protocol Comes Into Force, Internet available http://bbc.co.uk/i/hi/sci/tech/4267245.stm

Cox P, Betts R, and Acceleration of Global Warming due to carbon-cycle Jones C (2000) feed back in a coupled climate model Nature 408, 184 $-187$

Farrell $\mathrm{J}$ and Maskin Renegotiations in Repeated Games, Games and E (1989)

Economic Behaviour (4): 327 - 330

Friedlingstein $\mathrm{P}$, Climate - Carbon Feedback Analysis, results from Cox, Betts $\mathrm{R}$ et al C4MIP model intercomparison Journal of Climate 19, (2006) $3337-3353$

Friedman J (1986) 'Game Theory with Application to Economics', Oxford University Press, Oxford

Gorham E (1991) Northern Peatlands: Role in the Carbon Cycle and Probable Responses to Climate Warming Ecological Applications 1: 182 - 195, doi 10.2307/1941811

Hastings G (2006) 'Social Marketing' - Butterworth Heinemann, Burlington MA

IPCC (2000) 'Emission Scenarios, Summary for Policy Makers' Cambridge, Cambridge University Press

IPCC (2007) 'Climate Change 2007. The Physical Science Basis. Summary for Policy Makers', Cambridge University Press, Cambridge

Kotler P, Roberts, N 'Social Marketing' Thousand Oaks, Sage and Lee, N (2002)

Layard P (2005) 'Happiness: Lesson from a New Science', London: Allen Lane

Lazer W and Kelly E 'Social Marketing Perspectives and Viewpoints' (1973

Homewood IL, Richard D Irwin 
Meinshausen

(2006)
$\mathrm{M}$ 'What does a $2{ }^{\circ} \mathrm{C}$ target mean for greenhouse gas concentrations? A brief analysis based on multi- gas emissions Pathways and several climate sensitivity uncertainty estimates' pp $265-280$ in 'Avoiding Dangerous climate change', $\mathrm{H}$ J Schellnhuber et al (ed) Cambridge, Cambridge University Press

Nordhaus W and 'Warning the World - The Economics of the Boyer J (2000) Greenhouse Effect' Cambridge MA: MIT Press

Pittock, A Barrie 'Climate Change', London, Earthspan (2005)

Ruddiman W (2001) 'Earth's Climate: Past and Future', New York, WH Freeman and Co

Stem N (2006)

'Stem Review, Economics of Climate Change ', Cabinet Office- HM Treasury, Cambridge, Cambridge University Press

The Climate Group 'Carbon Down, Profits Up' Second Edition, 2005 (2005)

The Observer $25^{\text {th }}$ May 2008

The Observer "Poll: Most Britons Doubt Cause of Climate Change" $(22 / 06 / 08)$

Tol R (2002)

Estimation of the damage costs of climate change part II: dynamic estimates. Environmental and Resource Economics 21: 135 - 160

United Nations 'Negotiating the Protocol' (internet) Available Framework http://unfcc.int/kystro protocol/items/2830.php

Convention on

Climate Change

(UNFCCC) (2006) 